\title{
CULTURAL FILTERING IN LANGUAGE TRANSLATION
}

\begin{abstract}
Atikah Wati
Abstract

The aim of this paper is to find out the important of cultural filtering that used by translator in language translation. As we know that language and culture being inextricably interwoven, the transference of the linguistic expression is precisely an attempt to integrate elements of one culture into another. Translation, thus, becomes a cross cultural event and the translator has to formulate his translation strategies to translate source culture into target culture. To deal with these cultural problems, translator is supposed to insert cultural filter in the initial stage of understanding and analyzing codification of the source text in the first stance. Here the cultural filter helps translator in obtain various elements of source culture which cannot go as they are in the target culture because of cultural differences.
\end{abstract}

Keywords: language, culture, translation, cultural filtering .

\section{Introduction}

Studying on language, culture and translation and the relationship between them are valuable issues due to the importance of human communication in the world. The variety of languages with different cultures and necessity of communications in human life caused translation to be a very effective factor in communicating, exchanging cultures, and knowledge. Because of that, it seems that language and culture are closely related and it is essential to consider both in the process of translation.

Language and culture being inextricably interwoven, the transference of the linguistic expression is precisely an attempt to integrate elements of one culture into another. In this respect a translator must not be only multilingual but multicultural also. Translation involves translation of culture as, "One does not translate languages, one translates culture (...). That it is possible to translate one language into another at all attests to the universalities in culture, to common vicissitudes of human life, and to the like capabilities of men throughout the earth, as well as to the inherent nature of language and the character of the communication process itself..." (Casagrande 338).

Translation can be defined as the action or process of delivering text or message from one language into another. The process of translation is mainly a process of communication between different languages. Catford 91965) regards translation as "the replacement of textual material in one language $(\mathrm{S} \mathrm{L})$ by equivalent textual 
material in another language (T L). Catford's approach is the notion of 'equivalence' from S L (source language) to T L (target language).

The theory of translation has developed from the purely linguistic approach of 1960 `s through the textual focus of the late 1970`s to the culturally based orientation of today. Translation is viewed by exponents of this approach as a way of establishing contacts between cultures.

Translation becomes a cross cultural event and the translator has to formulate his translation strategies to translate source culture into target culture. It begins from the very choice of the text to be translated by the translator who has to keep acceptability and readability of the translated text in mind.

To deal with these cultural problems translator is supposed to insert cultural filter in the initial stage of understanding and analyzing codification of the source text in the first stance. Here the cultural filter helps him in obtain various elements of source culture which cannot go as they are in the target culture because of cultural differences.

\section{Discussion}

\section{Language}

There are lots of definitions on language which are included here shortly. Language is used to maintain and convey culture and cultural ties. Different ideas stem from differing language use within one's culture and the whole intertwining of these relationships start at one's birth. Language may refer either to the specifically human capacity for acquiring and using complex system of communication or to a specific instance of such a system of complex communication. The human language faculty is thought to be fundamentally different from and of much higher complexity than those of other species. Human language is highly complex in that it is based on a set of rules relating symbols to their meanings, thereby forming an infinite number of possible innovative utterances from a finite number of elements.

\section{Culture}

Newmark (1988) defined culture as "the way of life and its manifestations that are peculiar to a community that uses a particular language as its means of expression". He clearly stated that operationally he does not regard language as a component or feature of culture in direct opposition to the view taken by Vermeer who stated that "language is part of a culture." The term culture originally meant the cultivation of the soul or mind; culture includes behavior such as courtship or child rearing practices material things such as tools, clothing and shelter, institutions and beliefs. Culture is the sum total of the ways of living built up by a group and passed on from one generation to another. Culture is a complex whole which includes knowledge, belief, art, law, morals, customs and many other capabilities and habits acquired by man as a member of society. 


\section{Translation}

The communication of the meaning of the source-language text is by means of an equivalent target-language text so translation consists of language and culture. Two things are necessary for a good translation - an adequate understanding of the original language (source language) and an adequate command of the language into which one is translating (receptor language). Larson claimed that "Translation is a complicated process." However, a translator who is concerned with transferring the meaning will find that the receptor language has a way in which the desired meaning can be expressed, even though it may be very different from the source language form. Translation is no longer considered to be a mere cross-linguistic activity but it significantly is cross-cultural communication.

\section{The culture filter}

House (1977, 1981), Hervey and Higgins (1992) and Katan (1993) talk in terms of a 'culture filter' or 'cultural filter'. Katan (1999/2004) discusses four perception filters, based on neurolinguistic programming (NLP) theory, each of which is varyingly responsible for orienting or modelling the perception, interpretation and evaluation of (to use Goffman 1974) 'what it is that is going on'. The filters are: 'physiological', 'culture', 'individual' and 'language'.

All the filters function in the same way through modelling. A model is a (usually) useful way of simplifying and making sense of something which is complex, such as 'reality'. All models, according to Bandler and Grinder (1975), make use of three principles: deletion, distortion and generalization.

Hence, cultural filters (for Katan) are one of the four particular, but related, ways in which groups organize their shared (limited, distorted and stereotypical) perception of the world. This follows Goodenough's (1957/1964: 36) definition of culture as 'an organization.... It is the form of things that people have in mind, their model of perceiving, relating, and otherwise interpreting them'. For House (2006:349), on the other hand, 'A cultural filter is a means of capturing cognitive and socio-cultural differences' to be applied by translators, which for Katan is more closely related to the translator's capacity to mediate.

To what extent one filter prevails over another in translation is then the third area of controversy, With 'the cultural turn' (Lefevere and Bassnett 1990: 1), and Bassnett's proclaiming (1980/2002: 23) that 'the translator treats the text in isolation from the culture at his peril', the culture filter appeared to take the central stage. However, for Newmark (in Schaffner and Kelly-Holmes 1995: 80) there is 'an over-emphasis on going from one culture to another [due to] universal issues that go beyond culture. They're sometimes dressed in cultural clothes, but that's as far as it goes'. His views coincide with many professionals (Katan 2009). Others, again, believe that the filter should operate selectively. House (2006: 347), herself states that the 'cultural filter' should be 'inserted' only for certain text types, such as tourist information books and computer 
manuals. For Nida (1964: 130), on the other hand, the degree of intervention depends less on the text type itself than on the cultural and linguistic distance or gap between the languages concerned.

\section{The application of cultural filter}

Vermeer's definition, based on the first part of Goodenough's (1964: 36): 'Culture consists of everything one needs to know, master and feel, in order to assess where members of a society are behaving acceptably or deviantly in their various roles' (in Snell-Hornby 2006: 55). According to Snell-Hornby, it is also accepted by German-speaking translators as 'the standard'. Intervention at this level focuses on the skopos of the translation (Vermeer), and tailoring the translation according to reception in the target culture.

At this level of culture, linguistically we are no longer able to point to universal features that change label, or to culturemes that may require technical explication, but, as Sapir (1958: 214) emphasized, 'distinct worlds'.

So, cultures, here, are plural, and texts require mediating rather than conduit translation. Though Leppihalme restricts the term 'culture bumps' to 'the allusion [which] may remain unclear or puzzling' (1997: 4), the 'bump' can apply to any communication problem. It was coined by Archer (1986) as a mild form of 'culture shock', which has been defined as the 'emotional reactions to the disorientation that occurs when one is immersed in an unfamiliar culture and is deprived of familiar cues' (Paige 1993: 2).

The example below demonstrates the real-world problem bumps of transferring 'normal practice' with the conduit approach. A 1996 fax2, written in English from a firm in Pakistan to a well-known Italian fashion house with the intent of becoming a supplier, began as follows:

Attn: [name and department]

I made samples for you in 1994 for the summer and we had received orders for about 20,000 blouses to be shipped in 1995 but due to a plague in our country these orders were cancelled by you. The contact was made by (full name and full address).

This is not 'the normal' way to write a business letter of introduction in English. The introductory statement is too direct, personal and accusatory. Bentahila (2004) reports on a study of university students (Tetouan, Morocco) who used a similar more personal and emotive style to write a letter of application for study grants in the UK. Optimum relevance clearly comes from another local norm: 96 per cent, for example, expressed a desire to pursue personal ambitions (e.g. 'I don't exaggerate if I say that it is my dream'). 
Clearly, texts with a persuasive function, as above, must be manipulated if they are to function persuasively in the target culture. As Nida (2001: 37) puts it: 'Many translators believe that if they take care of the words and grammar, the discourse will take care of itself, but this concept results from an insufficient understanding of the role of discourse structures in interlingual communication'. He continues by noting that it is the 'intelligent secretaries in North America' who know how to delete overtly complimentary statements from Latins, and to add appropriate expressions of greeting and friendship from their North American bosses. Otherwise Latinos will think that American businessmen will be reluctant to do business with Latinos who appear to be too flattering and insincere.

The fact that he does not mention translators is striking but belies a fundamental issue: who actually acts as a cultural mediator? The 'translator', paradoxically, does not have the freedom a secretary has to facilitate communication, due both to domestic fidelity-to-the-text norms and to the (limiting) beliefs that professional translators themselves have about their role.

\section{Conclusion}

Culture is the total life way of people, the social legacy the individual acquires from his group. Culture would be transferred through language. Different language will create different world view. Moreover, translation seems to be the only possible way to "unite" all cultures in order to create cultural network, cultural globalization. In conclusion, it can be pointed out that translation process should be focused not only on language transfer but also - and most important - on cultural position. As an inevitable consequence of the previous statement, translators must be both bilingual and bicultural if not multicultural.

\section{References}

Abbasi, G., Zadeh, S. S., Janfaza, E., Assemi, A., Dehghan, S. S. 2012. language, translation, and culture. 2012 International Conference on Language, Medias and Culture IPEDR vol.33 (2012). IACSIT Press, Singapore.

Catford, J. C. 1965. A linguistic Theory of Translation. Oxford University Press.

Combrink, A. L. 2002. Mediating Intercultural Communication: the cultural filter and the act of translating/interpreting. Journal (ISSN 1023-1757)

Newmark. P. (1988). A Textbook of Translation. Prentice Hall.

Munday, J. 2009. The Routledge Companion to Translation Studies. Routledge.

Nida. E. (2001). Context in Translating. Oxford University Press. 
Reshi, N. A. 2012. Culture Based Translation and Its Strategies. International Indexed \& Referred Research Journal, ISSN-2250-2556; Vol.1, April, 2012. 